\title{
Opportunities for forming competitive advantages through transfer of technology
}

\author{
Darina Pavlova ${ }^{1}$, Sibel Ahmedova ${ }^{1}$ \\ ${ }^{1}$ Technical University of Varna, Department of Industrial Management, 9010, 1 Studentska Street, Varna, Bulgaria \\ Corresponding author contact: pavlovadeutu-varna.bg
}

\begin{abstract}
Issues relating to technical and technological procurement of the firms in Bulgaria, which determines their positions in the local, regional and global market are particularly topical. The article examines the transfer of technology as a factor for improving the firms' competitiveness and explores the opportunities for building competitive advantages through it. The practice of most developed countries proves conclusively that over the last few years the factor determining the macroand micro-level competitiveness is, in fact, the advancement in technology. Identified in the paper are the main priorities for the individual firms operating at the abovementioned levels of economic development.
\end{abstract}

Keywords: technologies, technology transfer, competitiveness, competitive advantage, innovations

\section{Introduction}

Technological development and innovations provide modern economy with considerable opportunities for building competitive advantages over their rivals. Regrettably, Bulgarian economy has failed so far to keep up with these trends. According to the World Competitiveness Yearbook published by the Institute for Management Development (IMD, Switzerland) Bulgaria in 2016 is ranked $55^{\text {th }}$ out of 61 economies, which is an improvement of 5 positions compared to 2015.

20062007200820092010201120122013201420152016

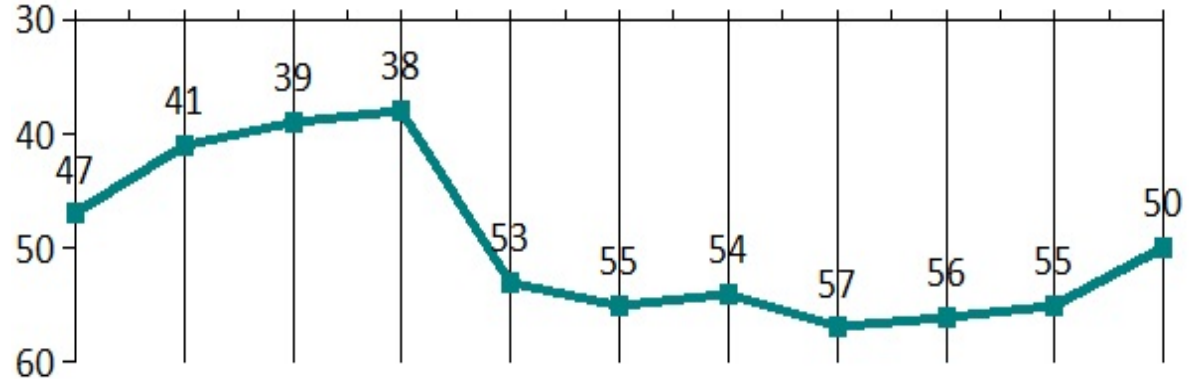

Fig. 1. Bulgaria's overall ranking 2006-2016 (Source: World Competitiveness Yearbook, 2016)

In spite of that fact, the Bulgarian economy remains among the most uncompetitive economies within the European Union member countries (with only Greece, Croatia and Ukraine having even lower rates). Bulgaria continues to lag behind in technological development and innovation performance with almost $60 \%$ relative to the average levels of EU -28 (Innovation Union Scoreboard 2015, Bulgaria country profile, EU, 2015, Brussels) as a factor for improving national competitiveness, regardless of the strategic framework, adopted in accordance with the EU requirements for the current 2014-2020 programming period.

To this effect, the creation, transfer and implementation of new technologies is one of the key possibilities for achieving continuous improvement and actual enhancement of competitiveness of Bulgarian enterprises and national economy, coping with intense pressure from competitive market forces within the global economy. 


\section{Technology transfer as a factor of competitiveness}

Analyzing critically and evaluating the key points and arguments made by various distinguished writers and notable economists (Bosco,M., 2001), (Bozeman, B., 2000), (Centron, M., 1974), ( Rogers, E., 1986), (Argote, L., Ingram P., Levine J.M. and Moreland R.L., 2000) it can be inferred that the transfer of technology is a complex and difficult process gradually evolving over time.

Continuously increasing competition forces the firms to seek ways to gain competitive advantages which determines the importance of innovations and transfer of technology (Dutta, S., Lanvin, B., \&Wunsch-Vincent, 2014.).

Technology transfer is an essential prerequisite for successful functioning of modern economy. It is the basis for the development of a contemporary enterprise and at the same time a driving factor for higher productivity, competitiveness and economic growth (Clark and Staunton, 1989,Clark and De Bresson,1990). Technology transfer is a means not only for overcoming successfully any technical and economic inconsistencies but also for achieving a more complete economic integration. In such a context, modern day researchers give priority to acquiring new technologies and know-how.

From a theoretical point of view, technology transfer can be defined as a process of transferring (disseminating) a set of combined technical, technological and organizational procurement mainly in two directions - from science into practice, when new knowledge is constructed and introduced for the first time, and between individual economic entities as regards its re-application and/or its subsequent modification. The transfer, by its very nature, brings together all forms and methods for application of technologies, know-how and collaboration within the respective spheres. The significance it has for the enterprises is determined by the possibility it raises for their improved competitiveness.

The achieved level of division of labour and the resultant increase in the mutual economic and technological dependence and between the separate branches, sub-branches, and types of production transforms the market economy into a structural and functional whole. Accordingly, along the chain of interbranch and intra-branch series of links "multiplied" are all qualitative and quantitative changes that would occur in the individual economic elements and subsystems. One of the key mechanisms through which the enterprises build up and sustain their competitive advantages is innovations, the multiplication of which is of paramount importance to the economy as a whole. Hence, the transfer of innovations can also be identified as a driver of the country's economic growth.

Technological procurement or "armament" is becoming a necessity for the enterprises, being at the same time directly dependent on the investment opportunities for its practical implementation. Putting the industrial sector under conditions of market competition in Bulgaria necessitates priority compliance with some financial indicators such as profitability and return of capital employed. It follows, therefore, that the modernization and renewal of technologies is appropriate in those sectors of the economy that are "viable" and can respond to new market requirements.

Enhancing competitiveness of the individual sectors and the firms operating in them is a key prerequisite for achieving economic growth, dealing with intense competitive pressure, and being thoroughly involved in the global division of labor.

Today's competitiveness is characterized by the potential for high productivity, which is based on an innovative approach to human resources, capital and physical assets. Adopting such an approach firms are capable of fighting off the challenges from national, international and global markets. Competitiveness refers to the ability of firms operating in a particular branch of industry to produce higher quality goods at lower costs in response to the needs of the end customer.

Market globalization and trade liberalization over the last few years have lessened the importance of lower- order comparative advantages - cheap labor, relatively cheap electricity, availability of raw materials. Higher-order advantages are becoming increasingly important- the ability of industries to develop high-tech manufacturing services, to produce and export goods with a higher degree of processing and greater intellectual content. The competitive potential in these industries presupposes their considerable impact on the competitiveness of the economy.

The extensive changes in the global economy result in wider deployment of competition between firms around the world. This requires all countries (including Bulgaria) as well as individual companies to adopt new strategies to enable them to develop competitive advantages based on knowledge and innovation. 
The practice in developed countries conclusively demonstrates that in recent years the factor determining the nature of industry competitiveness is technological development. It also establishes the main priorities for the individual companies operating in them. In the first place, successfully changing and developing companies are interested in drastically shortening the time between the creation of a given product and its introduction on the market. Another current trend emerges from the segmentation of the market. Consumers are becoming more and more demanding, and this in turn, forces the firms to search for one-off innovative solutions to meet the specific consumer requirements. And the third challenge relates to the very nature of competition governed predominantly by the existing technological opportunities. In a dynamically changing and evolving environment, firms are expected to maintain intensive interactions with diverse partners and contractors, to demonstrate specific technology-related capabilities and relevant capacity so as to qualify as partners in large consortium and international companies. The three trends hitherto discussed are mutually inclusive - they tend to combine, overlap and intertwine. Their powerful joint action forces companies to comply with them.

The reasoning given above proves conclusively that there is a close correlation and interdependence between technological transfer, innovation policy and industry competitiveness. Technological transfer is in fact one of the main means of achieving a competitive advantage.

Developing and sustaining innovation potential at a high-tech level, determining dynamic product portfolio and establishing stable market positions on international markets are very much dependent on the firm's business investment and innovation policy. The industry innovation policy is inherently directly proportional to and based on technology transfer. The interrelation between the two is conveyed by the fact that technology transfer is at the centre of innovation, be it related to techniques, technology or improvement of the whole industry and its proper management.

Undoubtedly, this depends, to a large extent, on the ability of the firms operating in the industry being discussed to respond adequately to the changes in their competitive environment, to seize every opportunity and make full use of the potential of the different forms and ways of accomplishing transfer of technology in order to achieve greater efficiency.

Furthermore, the constant improvement of the mechanism for ensuring the provision of new prospective ideas and technologies in the process of manufacturing, and their eventual transfer are decisive for the improvement of the enterprises' economic activities. As a result, they acquire considerable advantages over their competitors allowing them to achieve higher level of economic performance: they are more efficient; realize considerable growth; have greater market success and possess the potential to perceive and respond to new developments.

A major tool for facilitating company development and effecting innovativeness pertains to investments. If investments are made with the purpose of yielding profits from the invested financial resources, then the aim of innovations should consistently strive to improve the very object of investment.

One of the reasons for the decrease in the competitive ability of Bulgarian firms to perform successfully on the global market is their lower investment activity over the last few years. Investments are believed to be an effective means of acquiring innovation. The decline in the demand for individual highly specialized products with a higher degree of processing is a further obstacle to the development of clusters for the manufacturing of final goods with higher complexity and greater intellectual content. This provides solid grounds for the introduction of new technologies and means of production even within individual business organisations to be viewed as a factor for successful functioning and future development.

\section{Analysis of the use of European funding opportunities to support the transfer of knowledge and technology}

Bulgaria's membership in the EU presents a number of opportunities for Bulgarian firms to participate actively in various European programmes.

The main objectives and priorities of the available operational programmes are intended to improve the efficiency of enterprises and to encourage the development of favorable business environment by improving the existing technologies and management techniques, creating and commercializing inno- 
vation, protecting industrial property, upgrading the pro-innovative infrastructure, increasing both production and management capacity to create competitive advantages and to enhance the export potential, as well as promoting business co-operation and stimulating cluster formation.

The financial resources necessary for the improvement in the existing technologies and proper management of the enterprises involve procedures for technological modernization of the enterprises, complying with internationally recognized standards, introducing enterprise management systems and others. Thus, through purchasing and putting into service new machinery, plant and equipment representing long-term tangible fixed assets; purchasing and putting into service long-term intangible assets - software applications to ensure close monitoring of the production process and / or specialized computer applications for product design and development, patent rights, licenses and know-how, the firms can achieve lasting competitive advantages leading to a higher level of competitiveness.

Systematizing existing data, we can summarize the main points covered so far as follows: in the period from 2011 to the beginning of 2017 under OP "Competitiveness Development of the Bulgarian Economy "and OP "Innovation and Competitiveness" for improvement of technologies and enterprise management, the respective enterprises had received the total amount of $987041507 \mathrm{BGN}$ as state funding and 1900262723 BGN from the EU Structural and Cohesion Funds. All in all, funding has been granted to a total of 3800 enterprises on the territory of the country. Out of all funded enterprises $18 \%$ are small, $34 \%$ medium and $48 \%$ large -sized. ${ }^{1}$

The analysis shows that the highest relative share is allocated to projects for funding enterprises in the manufacturing sector $(61.29 \%)$, followed by the creation and dissemination of information and creative activities $(11.10 \%)$, professional and scientific research $(7.53 \%)$, hotels and restaurants $(1.22 \%)$ and mining and quarrying industry $0.38 \%$ (Fig. 1).

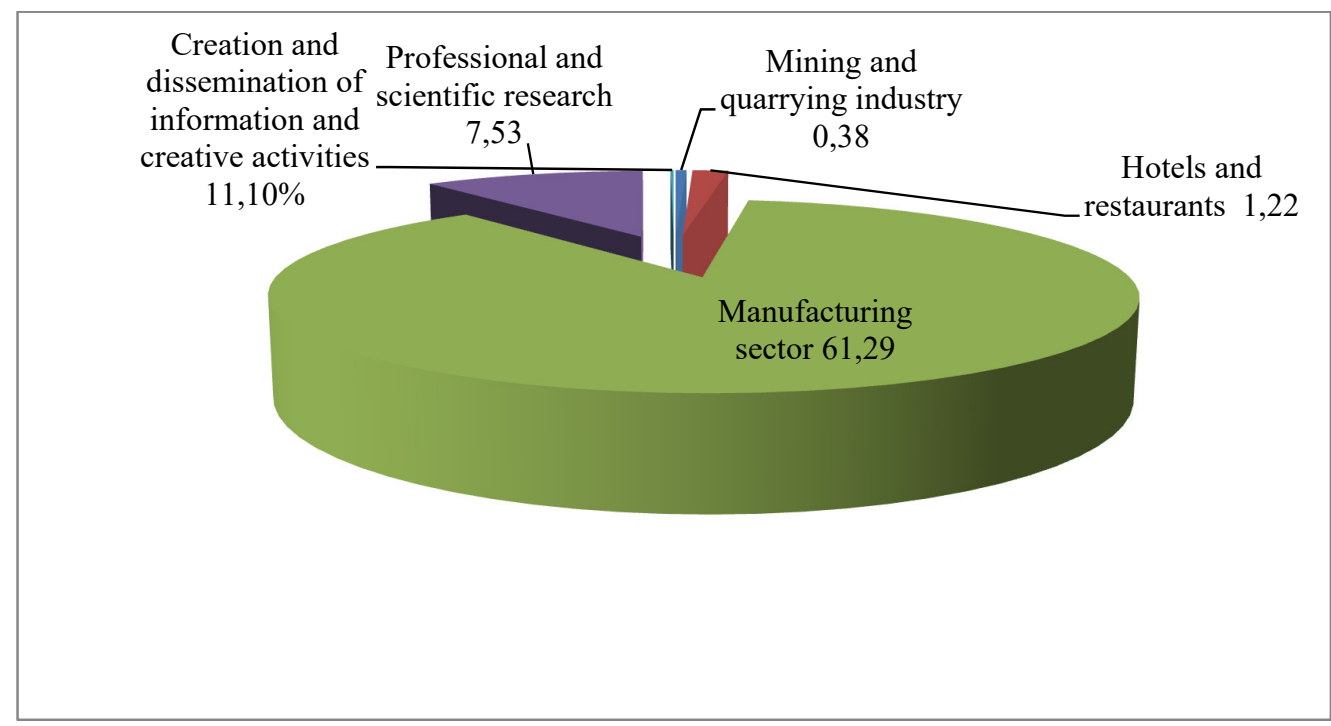

Fig.2. Sectoral impact of the absorbed funds

Quantitative research and evaluation has been applied to illustrate the significant financial resources received by the enterprises amounting to $522224198 \mathrm{BGN}$ as to the procedure for technological modernization. The number of funded enterprises is 998 and covers the period from 2011 until 2017. 94\% of the funded enterprises are small and medium, and only $6 \%$-large-sized. The total amount of budgetary funding to meet internationally recognized standards is $65324570 \mathrm{BGN}$, while the number of small, medium and large enterprises that have received financial resources is 824 , respectively. Only $2 \%$ of the surveyed enterprises have benefited from the possibilities of using research works developed by research teams and institutes as to the creation of new or improvement of the already existing products, services and processes. $60 \%$ of the enterprises have released improved versions of existing products, 
and $32 \%$ of the firms have plans to develop a new product / introduce innovation in their manufacturing processes for the following year. ${ }^{2}$

The analysis of the systematized information in Table 1 indicates that the budgetary sources of funding to meet internationally recognized standards amounts to $65324570 \mathrm{BGN}$, while the number of funded small, medium and large enterprises is 824 , respectively.

Table 1. Disbursementoffundsto SMEs

\begin{tabular}{|lcc|}
\hline Financing direction & $\begin{array}{c}\text { Projects / } \\
\text { pc. }\end{array}$ & $\begin{array}{c}\text { Amount of budgetary } \\
\text { financing / BGN. }\end{array}$ \\
\hline Covering internationally recognized standards & 824 & 65324570 \\
\hline Technological modernization & 998 & 522224198 \\
\hline Total: & 1822 & 587548768 \\
\hline
\end{tabular}

The procedure for the established quality standards of the manufactured products is related to the introduction and effective implementation of the standard requirements and is considered one of the main factors for the competitive development of enterprises. The focus is on the quality management standards ISO 9001, safe food production (HACCP and / or ISO 22 000) and safe working conditions (OHSAS 180001).

As depicted in fig. $2,43 \%$ of small and medium and $53 \%$ of large-scale enterprises have an international standard introduced as a result of financial assistance under OP "Development of the Competitiveness of the Bulgarian Economy" and OP "Innovations and competitiveness".

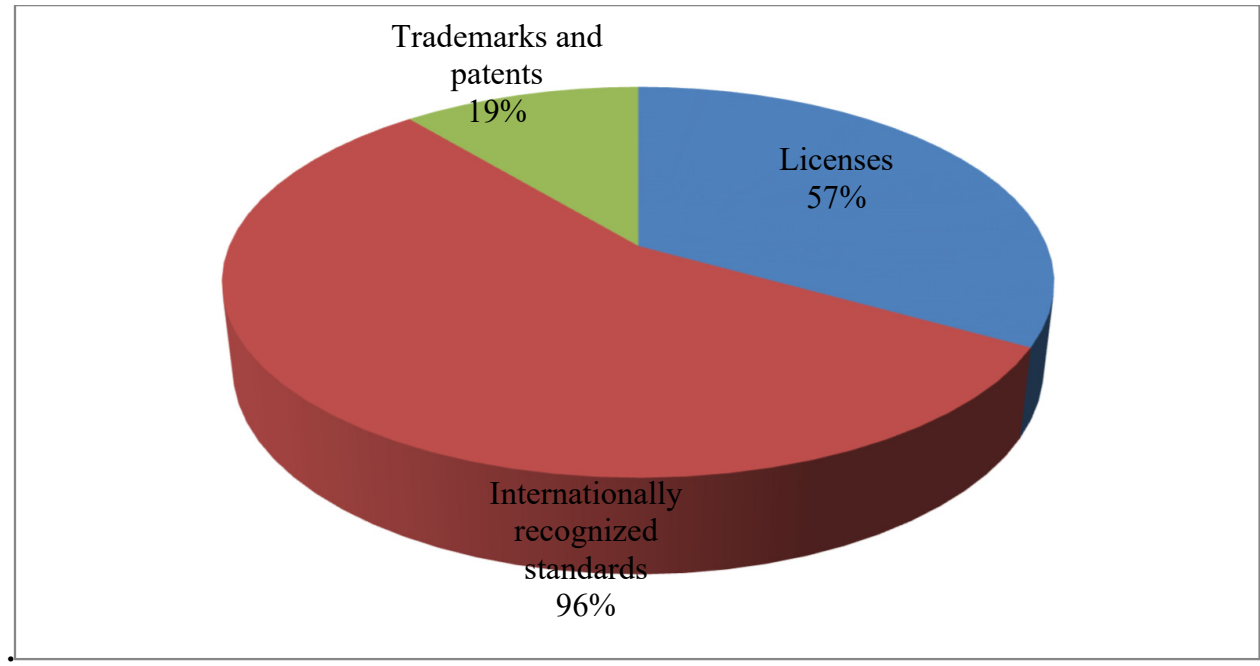

Fig.3. Improvement in technologies and enterprise management

The advanced analysis outlines the different characteristic features of technological development. The registered trademarks and patents specify the degree of protection of the manufactured products. Often the presence of a trademark serves to ensure the quality of the final products. The commercial value of the brands and the importance the trade marks might have, determine the market success of a given product. Only $19 \%$ of the funded enterprises have invested the acquired funds for obtaining patents. Rating based on the size of the enterprise shows that 3\% of them are small, $7 \%$-medium and $9 \%$ -large -sized; $57 \%$ of the funded enterprises have acquired licenses. Of these $29 \%$ are medium and $17 \%$ -large enterprises.(Fig.3)

${ }^{2}$ http://umispublic.government.bg/prProcedureProjectsInfo.aspx $?$ op $=5 \&$ proc $=373$ 
The summary made on the basis of the conducted research and the analysis of the collected data, is as follows:

As a result of successful project implementation, the funded enterprises have achieved:

- expanding production capacity and a significant increase in the quantity of manufactured final products;

- achieving lower cost per unit of output;

- product diversification;

- expanding market positions;

- enhanced employment opportunities within the firm itself - new jobs have been created;

- minimizing risk and firm's dependence on suppliers

\section{Guidelines for enhancing competitiveness through transfer of technology}

The priorities for development of national economy in the context of the country's EU membership and the dynamic processes occurring in the global economy have resulted in fierce competitive rivalry. This requires Bulgarian enterprises to focus further efforts on increasing their innovative potential by stimulating на transfer of technology, provision of networking and closer cooperation between the scientific research and business communities.

To this effect, put forward in the paper are the following basic guidelines for improved innovativeness and competitiveness of the Bulgarian enterprises:

- Encouraging entrepreneurship for the effective use of various channels and forms of technology transfer;

- Promoting technological innovation through remuneration of intellectual creativity;

- Introduction of information technology support at all levels of the organization and management of the enterprise;

- Improved investments in: human capital, science and quality of education ;

- Fostering inter-company co-operation and collaboration;

- Developing a system for protection and use of objects of intellectual property;

- Intensifying the process of creation of innovation clusters and centers for technology transfer;

- Encouraging competition and investments in developing new or improved products or processes, by stimulating research and development activities;

- Facilitating transfer of technology through publicly available databases for patents, technical standards, scientific and technical innovations and market research, legislation and regulatory compliance.

\section{Conclusion}

Nowadays the transfer of technology has become an effective tool for competitive micro- and macroinnovation development. Its significance is determined by the following main reasons:

1. The processes of global development have opened up new opportunities for national companies to enter new markets and gain considerable advantages offered by novel sources of investment and cutting-edge technology;

2. Intensifying the competitive rivalry in the area of high technology;

3. Striving to enhance the effective use of the results of scientific and technological activity for business purposes;

4. Motivating the firms to increase spending on research and development.

5. For Bulgarian enterprises, the transfer of technology is a great opportunity to receive process and effectively use information based on knowledge, increase their overall performance and competitiveness, which is the true basis for further development and prosperity. 


\section{References}

Argote L., Ingram P., Levine J.M. and Moreland R.L., (2000), Knowledge transfer in organizations, Organisational Behavior and Human Decision Processes 82 (1), pp.1-8

Bosco, M. J., (2001), Integration, technological transfer and intellectual property rights: an empirical application to the MENA contries Ph.D. Thesis, Bocconi University, Milan

Bozeman, B. (2000), Technology transfer and public policy: a review of research and theory. Research policy, 29(4), 627-655

Centron, M., (1974) Technology Transfer: Where We Stand Today. Technology Transfer.Ed.ByH.Davidson. Noordhoff-Lieden

Clark,P., and Staunton,N.,(1989), Innovation in Technology and Organization, London, Routledge

Clark,P., and De Bresson,C., (1990), Innovation - design and innovation poles, in R.Loveridge and M.Pitt (eds), The Strategic Management of Technological Innovation, Chichester: Wiley

Dutta, S., Lanvin, B., \&Wunsch-Vincent, S. (2014). The Global Innovation Index 2014: The Human Factor in Innovation. Geneva: Worl Intellectual Property Organization. Retrieved from http://www.globalinnovationindex.org/userfiles/file/reportpdf/GII-2014-v5.pdf.

Rogers, E. M. 1986. Models of knowledge transfer: Critical perspectives. In: Beal, G. M., Dissanayake, W.,Konoshima, S. (Eds), Knowledge Generation, Exchange and Utilization, Boulder (Colorado): Westview Press, 37-60.

http://umispublic.government.bg/opPriorityLines.aspx?op=5

https://eumis2020.government.bg/bg/s/Procedure/Active

World Competitiveness Yearbook, 2016 